\title{
Effect of Insect Growth Regulators on Citrus Mealybug [Planococcus citri (Homoptera: Pseudococcidae)] Egg Production
}

\author{
Raymond A. Cloyd \\ University of Illinois, Department of Natural Resources and Environmental \\ Sciences, 384 National Soybean Research Laboratory, 1101 West Peabody \\ Drive, Urbana, IL 61801 \\ Additional index words. coleus, insect growth regulators, kinoprene, pyriproxyfen, \\ buprofezin, novaluron, azadirachtin, interiorscapes, mealybugs
}

\begin{abstract}
Greenhouse trials were conducted in 2000-2001 to evaluate the indirect effects of insect growth regulators, whether stimulatory or inhibitory, on the egg production of female citrus mealybug [Planococcus citri (Risso)]. Green coleus [Solenostemon scutellarioides (L.) Codd] were infested with 10 late third instar female citrus mealybugs. The insect growth regulators kinoprene, pyriproxyfen, azadirachtin, buprofezin, and novaluron were applied to infested plants at both the high and low manufacturer recommended rates. Beginning two days after treatments were applied, plants were monitored daily to determine when female mealybugs began to oviposit. Individual mealybugs were removed from plants, placed into glass vials containing $70 \%$ isopropyl alcohol when female mealybugs started to oviposit, and dissected to determine the number of eggs. Overall, there were no consistent patterns to suggest that the insect growth regulators and different rates tested had any effect on the egg production of citrus mealybug females. Although, in one instance, the insect growth regulators kinoprene and pyriproxyfen actually lowered citrus mealybug egg production. In addition, the insect growth regulator buprofezin numerically increased female citrus mealybug egg production.
\end{abstract}

Citrus mealybug is a major arthropod pest in interior plantscape environments, including greenhouses, conservatories, and interiorscapes (Kole and Hennekam 1990). In addition to removing plant fluids by feeding, citrus mealybugs exude large quantities of honeydew that serves as a growing medium for sooty mold fungi. In addition, honeydew attracts ants, which protect mealybugs from parasitoids and predators that are used to manage this pest in interior plantscapes (Copland et al., 1985). The number of eggs laid by adult female citrus mealybugs is temperature dependent with females laying $<100$ eggs at temperatures above $30{ }^{\circ} \mathrm{C}$, but laying over 400 eggs at $18{ }^{\circ} \mathrm{C}$ (Copeland et al., 1985). It is important, because of the large number of eggs produced, to prevent female citrus mealybugs from reaching the adult stage. In addition, the waxy covering of adults protects them somewhat from conventional insecticides (Copland et al., 1985).

Due to the amount of public traffic and the potential public exposure to insecticides in interiorscapes and conservatories, the types of insecticides that can be used to manage insects are limited. As a result, there is an increased interest and use of materials classified as reduced-risk. Reduced-risk insecticides are less

\footnotetext{
Received for publication 24 Apr. 2003. Accepted for publication 17 July 2003. Thanks to R. Weinzierl and R. Skirvin, Univ. of Illinois, Champaign-Urbana, for commenting on previous versions of this manuscript. This research was supported by Hatch Project Funds provided by the state of Illinois.
}

toxic to humans, safe to nontarget organisms, leave minimal toxic residues, and are shortlived in the environment (Lowery and Isman, 1995; Parrella et al., 1983), which is why they are used in interior plantscapes. Insecticides classified as reduced-risk include insecticidal soaps, horticultural oils and insect growth regulators.

The two primary categories of insect growth regulators are the juvenile hormone mimics or analogs, and chitin synthesis inhibitors. Juvenile hormone mimics arrest insect development so insects are unable to complete their lifecycle. As a result, insects either fail to reach adulthood because they die in the immature stage, or they mature into sterile adults. Chitin synthesis inhibitors affect the insect's ability to molt by preventing the formation of chitin, which is an essential component of an insect's exoskeleton. As such, insects are killed while molting from one instar to the next (Olkowski et al., 1991; Ware, 2000). In addition to the use of systemic insecticides such as imidacloprid, insect growth regulators, which are active only on the mealybug larval and pupal stages, are another option to manage citrus mealybugs in interior plantscapes (Lindquist, 1981).

In interiorscapes or conservatories, there are commonly overlapping generations such that all developmental stages (i.e., egg, larvae, pupae, and adult) are present at the same time (Gill, 1988). Although insect growth regulators are used to kill immature stages, they may have indirect effects such as reducing or increasing citrus mealybug egg production. The stimulation of an organism to increase reproduction as a result of insecticide applications is referred to as "hormoligosis" (Luckey, 1968). Hormoligosis has been implicated in the increase of female fecundity in several insect species such as Scirtothrips citri (Moulton) (Morse and Zareh, 1991), Callosobruchus maculatus (F.) (Lale 1991),Zabrotes subfasciatus (Boheman), and Acanthoscelides obtectus (Say) (Weaver et al., 1992). Low doses of conventional insecticides have been implicated in increasing the fecundity of certain pests, including Coccus hesperidum (L.) (Hart et al., 1966). In addition to increasing egg production, insecticides may also alter insect sex ratios (Dittrich et al., 1974).

Some insect growth regulators that act as juvenile hormone mimics reduce reproduction by sterilizing females (Hamlen, 1977). In fact, insect growth regulators have been shown to drastically reduce the fecundity of beneficial insects such as the ladybird beetles, Adalia bipunctata L. and Coccinella septempunctata L.(Olszak etal., 1994). Regardless, there is still minimal information on the potential indirect effects of insect growth regulators on arthropod pests such as citrus mealybug.

The objective of this study was to determine if insect growth regulators have any indirect effect on mealybugs by evaluating whether selected commercially available insect growth regulators increase, decrease, or have no effect on female citrus mealybug egg production.

\section{Materials and Methods}

The effect of several selected insect growth regulators on female citrus mealybug egg production was determined in two trials in 2000 and 2001.

Study 1, 2000. Forty green coleus started from cuttings taken from stock plants (originally obtained from a greenhouse at Purdue Univ., West Lafayette, Ind.) were placed into 15.2-cm plastic containers (T.O. Plastics, Minneapolis) in a growing medium consisting of $70 \%$ to $80 \%$ Canadian sphagnum peat moss, perlite, dolomitic limestone, gypsum, and a wetting agent. Plants were fertilized with a $20.0 \mathrm{~N}-16.6 \mathrm{P}-8.8 \mathrm{~K}$ at $200 \mathrm{~mL} \cdot \mathrm{L}^{-1} \mathrm{~N}$ in a constant liquid feed program. Coleus were grown in a glass greenhouse $\left(6.1 \times 3.0 \mathrm{~m}=18.3 \mathrm{~m}^{2}\right)$ and placed on wire-mesh raised benches $2.1 \mathrm{~m}$ long $\times 1.4 \mathrm{~m}$ wide. The greenhouse temperature was maintained at $24 \pm 5{ }^{\circ} \mathrm{C}$, and $50 \%$ to $60 \%$ relative humidity $(\mathrm{RH})$.

When the 40 plants were an average of $43.3 \mathrm{~cm}$ in height for trial $1(\mathrm{n}=10)$ and 33.3 $\mathrm{cm}$ in height for trial $2(\mathrm{n}=10)$, they were each artificially infested with 10 late third instar (3.2 to $3.5 \mathrm{~mm}$ long) female citrus mealybugs. The mealybugs were obtained from a laboratory colony reared on butternut squash [Cucurbita maxima (L.)] in a growth chamber maintained at $23.9 \pm 5{ }^{\circ} \mathrm{C}, 50 \%$ to $60 \% \mathrm{RH}$, and photoperiod of 14:10 (L:D) hours. Mealybugs were randomly placed onto fully expanded leaves of each plant. The mealybugs were then allowed to settle for $2 \mathrm{~d}$ before treatments were applied. Three insect growth regulators (treatments) were used at both the low and high label rates. 
All applications were made using a 1.0L plastic spray bottle (ProSafe All Purpose Sprayer, Contico, St. Louis). All plants were sprayed to run-off with $70 \mathrm{~mL}$ of spray solution. Deionized water was used for all treatments. There were five replicates (plants) per treatment with each plant containing 10 female citrus mealybugs.

The treatments were kinoprene (Enstar II; Wellmark Intl., Bensenville, Ill.) at 0.37 and $0.74 \mathrm{mLL}^{-1}$, pyriproxyfen (Distance; Valent USA Corp., Walnut Creek, Calif.) at 0.59 and $0.89 \mathrm{mLL}^{-1}$, and azadirachtin (Ornazin; SePRO Corp., Carmel, Ind.) at 0.59 and $0.74 \mathrm{mLL}^{-1}$, and an untreated check (control). All three of these insect growth regulators are juvenile hormone mimics.

Beginning $2 \mathrm{~d}$ after treatments were applied, plants were monitored daily to determine when female mealybugs began to oviposit. Mealybugs were removed from coleus plants using micro-forceps when the females began to oviposit. The initiation of oviposition was determined when the white tuft of wax beneath the female abdomen was clearly visible. Most mealybugs started ovipositing within 7-10 d after treatments had been applied. Females and eggs laid in the tuft of wax were preserved in $70 \%$ isopropyl alcohol until dissected to determine egg load.

Study 2, 2001. This study was similar to the previous study except that 30 coleus plants were used. Plants used in both trials were an average of $26.0 \mathrm{~cm}$ in height when each plant was artificially infested with 10 late third instar (3.2 to $3.5 \mathrm{~mm}$ long) female citrus mealybugs. In addition, this study evaluated two different insect growth regulators (treatments) at two different rates.

The treatments were buprofezin (Talus; SePro Corp., Carmel, Ind.) at $0.14 \mathrm{~g} \cdot \mathrm{L}^{-1}$ and $0.28 \mathrm{~g} \cdot \mathrm{L}^{-1}$, novaluron (Pedestal; Uniroyal Chemical Co., Middlebury, Conn.) at 0.22 and $0.88 \mathrm{mLL}^{-1}$, and an untreated check (control). Both these insect growth regulators are chitin synthesis inhibitors.

All data from both studies were analyzed in a completely randomized design using a two-way analysis of variance (SAS Institute, 2000) to determine the effect of treatment and rate on citrus mealybug egg production. Significant treatments and rates were separated using a Student-Newman-Keuls (SNK) mean separation test.

\section{Results and Discussion}

Study 1, 2000. Although there was a significant effect of rate for both trials (trial $1, F=$ 5.82; df $=3,79 ; P=0.0001$; trial $2, F=4.16$; df $=3,79 ; P=0.0002)$, this difference was between the insect growth regulators tested and the rates used. There was no significant difference from the control treatment for trial 1 (Table 1). What is most important is that there were no consistent patterns or trends in the data between the trials to substantiate any influence of the insect growth regulators on female egg production. In trial 2 , the reason there were significant differences between several of the insect growth regulators and the control treat-

Table 1. Citrus mealybug egg production per female for the low and high-labeled rates of all treatments for both trials in study 1, year 2000 (mean \pm SE).

\begin{tabular}{|c|c|c|c|c|c|}
\hline \multirow[b]{3}{*}{ Treatment } & \multirow[b]{3}{*}{ Rate } & \multicolumn{4}{|c|}{ Mealybug egg production per female } \\
\hline & & \multicolumn{2}{|r|}{ Trial 1} & \multicolumn{2}{|c|}{ Trail 2} \\
\hline & & $\begin{array}{c}\text { No. } \\
\text { mealybugs }\end{array}$ & Mean $( \pm$ se $)$ & $\begin{array}{c}\text { No. } \\
\text { mealybugs }\end{array}$ & $\operatorname{Mean}( \pm \mathrm{se})$ \\
\hline Azadirachtin & $0.59 \mathrm{~mL} \cdot \mathrm{L}^{-1}$ & 10 & $171.4( \pm 11.6) \mathrm{ab}^{2}$ & 10 & $142.3( \pm 8.1) \mathrm{ab}$ \\
\hline Azadirachtin & $0.74 \mathrm{~mL} \cdot \mathrm{L}^{-1}$ & 10 & $195.6( \pm 9.5)$ a & 10 & $130.5( \pm 7.9) \mathrm{abc}$ \\
\hline Kinoprene & $0.37 \mathrm{~mL} \cdot \mathrm{L}^{-1}$ & 10 & $134.9( \pm 6.1) b$ & 10 & $130.3( \pm 6.9) \mathrm{abc}$ \\
\hline Kinoprene & $0.74 \mathrm{~mL} \cdot \mathrm{L}^{-1}$ & 10 & $173.8( \pm 7.3) \mathrm{ab}$ & 10 & $151.9( \pm 12.9) \mathrm{a}$ \\
\hline Pyriproxyfen & $0.59 \mathrm{~mL} \cdot \mathrm{L}^{-1}$ & 10 & $137.2( \pm 7.3) b$ & 10 & $155.3( \pm 8.2) \mathrm{a}$ \\
\hline Pyriproxyfen & $0.89 \mathrm{~mL} \cdot \mathrm{L}^{-1}$ & 10 & $154.2( \pm 7.3) b$ & 10 & $127.7( \pm 6.2) \mathrm{abc}$ \\
\hline Control & & 10 & $162.3( \pm 7.0) \mathrm{ab}$ & 10 & $104.5( \pm 5.2) \mathrm{c}$ \\
\hline
\end{tabular}

${ }^{\mathrm{z}}$ Means not followed by a common letter within each row are significantly different $(P=0.05)$ asdetermined by Student-Newman-Keuls (SNK) mean separation test.

Table 2. Citrus mealybug egg production per female for the low and high-labeled rates of all treatments for both trials in study 2, year 2001 (mean \pm SE).

\begin{tabular}{|c|c|c|c|c|c|}
\hline \multirow[b]{3}{*}{ Treatment } & \multirow[b]{3}{*}{ Rate } & \multicolumn{4}{|c|}{ Mealybug egg production per female } \\
\hline & & \multicolumn{2}{|r|}{ Trial 1} & \multicolumn{2}{|c|}{ Trail 2} \\
\hline & & $\begin{array}{c}\text { No. } \\
\text { mealybugs }\end{array}$ & Mean $( \pm$ se $)$ & $\begin{array}{c}\text { No. } \\
\text { mealybugs }\end{array}$ & Mean $( \pm$ se $)$ \\
\hline Buprofezin & $0.14 \mathrm{~mL} \cdot \mathrm{L}^{-1}$ & 10 & $181.7( \pm 9.8) \mathrm{a}^{\mathrm{z}}$ & 10 & $186.7( \pm 11.3) b$ \\
\hline Buprofezin & $0.28 \mathrm{~mL} \cdot \mathrm{L}^{-1}$ & 10 & $181.7( \pm 8.6) \mathrm{a}$ & 10 & $246.1( \pm 21.5) \mathrm{a}$ \\
\hline Novaluron & $0.22 \mathrm{~mL} \cdot \mathrm{L}^{-1}$ & 10 & $144.1( \pm 8.4) b$ & 10 & $175.5( \pm 10.5) b$ \\
\hline Novaluron & $0.88 \mathrm{~mL} \cdot \mathrm{L}^{-1}$ & 10 & $164.7( \pm 7.6) \mathrm{ab}$ & 10 & $188.5( \pm 8.4) b$ \\
\hline Control & & 10 & $157.4( \pm 9.2) \mathrm{ab}$ & 10 & $188.1( \pm 9.1) b$ \\
\hline
\end{tabular}

${ }^{2}$ Means not followed by a common letter within each row are significantly different $(P=0.05)$ as determined by Student-Newman-Keuls (SNK) mean separation test.

ment may be due to the low number of eggs laid in the control treatment (Table 1). These data suggest that the insect growth regulators at both the high and low rates did not affect mealybug egg production as the treatments in general were only numerically or biologically different; not statistically. However, it is possible that the insect growth regulators tested may have actually delayed egg production instead of reducing egg production. This may be due to the mealybug instar used, which may have been far enough along in oviposition that it diminished the impact of the treatments. Overall, the insect growth regulators tested and at different rates did not affect mealybug egg production, although mealybugs treated with kinoprene and pyriproxyfen did produce fewer eggs in trail 1.

Study 2, 2001. Despite the significant rate comparison for both trials (trial $1, F=3.19$; df $=2,59 ; P=0.0081 ;$ trial $2, F=4.17$ df $=$ 2,$59 ; P=0.0012$ ) in which both buprofezin and novaluron did not affect mealybug egg production (Table 2) there were no consistent patterns or trends between the trials to indicate that the insect growth regulators affected egg production. However, mealybugs on coleus plants treated with the high rate of buprofezin produced significantly more eggs than both rates of novaluron, the low rate of buprofezin, and the control treatment (Table 2).

High-labeled rates of conventional insecticides have been responsible for reducing fecundity of citrus thrips [Scirtothrips citri (Moulton)] (Morse and Zareh, 1991). However, reproduction may be increased by certain concentrations of insecticides (Luckey, 1968). Low doses of insecticides may induce higher reproductive rates in target pests. For example, parathion applications caused brown soft scale [Coccus hesperidum (L.)] to repro- duce at higher levels (Hart et al., 1966; Hart and Ingle, 1971). In this study, the rates used did not influence mealybug egg production. This may be a function of the mode of action differences between conventional insecticides, which act as nerve toxins compared to insect growth regulators that are active on the insect hormonal system or on chitin synthesis.

The insect growth regulator buprofezin reduces the fecundity of adult female greenhouse whitefly [Trialeurodes vaporariorum Westwood] and also reduces egg hatchability (Yasui et al., 1987). Additionally, buprofezin has been shown to be effective in controlling citrus mealybug, especially at high label rates (Bedford et al., 1996); however, in this study, the mealybugs treated with buprofezin (at sublethal rates) numerically laid more eggs than the novaluron and control treatments. It is possible that any potential stimulatory effect may be due to the impurities in the insecticide formulation and not necessarily the active ingredient (Luckey, 1968).

This study is the first to initially determine if currently registered insect growth regulators have any indirect effects on citrus mealybugs. Overall, this study has demonstrated that insect growth regulators generally have minimal effect on the egg production of citrus mealybug. Additionally, because the differences in female mealybug egg production among the insect growth regulators tested were minimal it is unlikely that these materials would strongly influence population development in interior plantscapes. Although, in one instance, the insect growth regulators kinoprene and pyriproxyfen actually lowered citrus mealybug egg production. In addition, the insect growth regulator buprofezin numerically increased citrus mealybug egg production. This information is important to interiorscape managers and con- 
servatory curators as pest control materials such as insect growth regulators are one of the few options available and may be used to deal with arthropod pests such as citrus mealybug.

\section{Literature Cited}

Bedford,I.D.,A. Kelly, and P.G. Markham. 1996. The effects of buprofezin against citrus mealybug, Planococcus citri. Brighton Crop Protection Conference: Pests and diseases, p. 1065-1070. In: Proc. Intl. Conf., Brighton, U.K.

Copland, M.J.W., C.C.D. Tingle, M. Saynor, and A. Panis. 1985. Chapter 2.9: Biology and glasshouse mealybugs and their predators and parasitoids, p. 82-86. In: N.W. Hussey and N. Scopes (eds). Biological control: The glasshouse experience. Cornell Univ. Press, Ithaca, N.Y.

Dittrich, V., P. Streibert, and P.A. Bathe. 1974. An old case reopened: Mite stimulation by insecticide residues. Environ. Entomol. 3:534-540.

Gill, R.J. 1988. The scale insects of California, Part 1: The soft scales (Homoptera: Coccoidea: Coccidae). California Dept. of Food and Agr., Sacramento.

Hamlen, R.A. 1977. Laboratory and greenhouse evaluations of insecticides and insect growth regulators for control of foliar and root infesting mealybugs. J. Econ. Entomol. 70:211-214.
Hart, W.G. and S. Ingle. 1971. Increases in fecundity of brown soft scale exposed to methyl parathion. J. Econ. Entomol. 64:204-208.

Hart, W.G., S. Ingle, M. Garza, and M. Mata. 1966. The response of brown soft scale and its parasites to repeated insecticide pressure. J. Rio Grande Valley Hort. Soc. 20:64-68.

Kole, M. and M. Hennekam. 1990. Update: Six years of successful biological control in interior plantscapes in the Netherlands. The IPM Practitioner 12:1-4.

Lale, N.E.S. 1991. The biological effects of three essential oils on Callosobruchus maculatus (F.) (Coleoptera: Bruchidae). J. African Zoo. 105:357-362.

Lindquist, R.K. 1981. Controlling the citrus mealybug on greenhouse foliage plants. Ohio Florists' Assn. Bul. 622:6-8.

Lowery, D.T. and M.B. Isman. 1995. Toxicity of neem to natural enemies of aphids. Phytoparasitica 23(4):297-306.

Luckey, T.D. 1968. Insecticide hormoligosis. J.Econ. Entomol. 61(1):7-12.

Morse, J.G. and N. Zareh. 1991. Pesticide-induced hormoligosis of citrus thrips (Thysanoptera: Thripidae) fecundity. J. Econ. Entomol. 84(4): 1169-1174.

Olkowski, W., S. Daar, and H. Olkowski. 1991.
Common sense pest control. Taunton Press, Newton, Conn.

Olszak, R.W., B. Pawlik, and R.Z. Zajac. 1994. The influence of some insect growth regulators on mortality and fecundity of the aphidophagous coccinellids Adalia bipunctata L. and Coccinella septempunctata L. (Col., Coccinellidae). J. Appl. Entomol. 117:58-63.

Parrella, M.P., G.D. Christie, and K.L. Robb. 1983. Compatability of insect growth regulators and Chrysocharis parksi (Hymenoptera: Eulophidae) for the control of Liriomyza trifolii (Diptera: Agromyzidae). J. Econ. Entomol. 76(4):949-951.

SAS Institute. 2000. SAS System for Windows, version 8.0. SAS Inst., Cary, N.C.

Ware, G.W.2000. The pesticide book. W.H. Freeman and Co., San Francisco.

Weaver, D.K., F.V. Dunkel, J.L. Cusker, L. van Puyvelde, and L. Van Puyvelde. 1992. Oviposition patterns in two species of bruchids (Coleoptera: Bruchidae) as influenzed by the dried leaves of Tetradenia riparia, a perennial mint (Lamiales: Lamiaceae) that suppresses population size. Environ. Entomol. 21:1121-1129.

Yasui, M., M. Fukada, and S. Maekawa. 1987. Effects of buprofezin on reproduction of the greenhouse whitefly, Trialeurodes vaporariorum (Westwood) (Homoptera: Aleyrodidae). Appl. Entomol. Zool. 22(3):266-271. 